\title{
Rubem Alves: El Pensamiento Poético-Teológico en Libertad Total1
}

\author{
Leopoldo Cervantes-Ortiz²
}

\begin{abstract}
Descubrí la poesía tardíamente, después de rebasar los cuarenta años. ¡Qué pena! ¡Cuánto tiempo perdido! La poesía es unja de mis mayores fuentes de alegría y sabiduría. Como dice [Gaston] Bachelard: "Los poetas nos dan una gran alegría de palabras...".3
\end{abstract}

Todo empezó entre 1981 y 1983 con Variações sobre a vida e a morte. O feitiço erético-erótico da teologia (La teología como juego, en español) y Poesia, profecia, magia. Meditaçōes, volúmenes que le sirvieron a Rubem Alves para, en el primer caso, replantear su visión completa de la nueva teología que comenzó a hacer y, en el segundo caso, para reelaborar los textos breves que comenzó a publicar en la revista Tempo e Presença. Alves comenzaba a experimentar la libertad expresiva total que no abandonaría nunca y que le permitió ubicarse como uno de los mejores escritores brasileños de la segunda mitad del siglo XX. En su campo específico, en el diálogo con lo religioso, es quizá el mayor de todos, pues como bien lo dijo en varias ocasiones, consiguió romper con todas las limitaciones académicas y su pensamiento poético-teológicoreligioso salió definitivamente de las jaulas impuestas por los dogmas y las instituciones. La poesía lo estaba esperando, acechando, para venir sobre él como una revelación, tal como dio testimonio cuando se conectó con la sección titulada precisamente "La revelación poética", en El arco y la lira (1956) de Octavio Paz, Premio Nobel mexicano. Paz lo llevaría de la mano hacia la otredad, hacia la otra cara de las cosas, hacia nuevas e impredecibles revelaciones, a "la sílaba olvidada del comienzo".

Todos los días cruzamos la misma calle o el mismo jardín; todas las tardes nuestros ojos tropiezan con el mismo muro rojizo, hecho de ladrillo y tiempo urbano. De pronto, un día cualquiera, la calle da a otro mundo, el jardín acaba de nacer, el muro fatigado se cubre de signos. Nunca los habíamos visto y ahora nos asombra que sean asi: tanto y tan abrumadoramente reales. Su misma compacta realidad nos hace dudar: ¿son así las cosas o son de otro modo? No, esto que vemos por primera vez ya lo habíamos visto antes. En algún lugar, en el que acaso nunca hemos estado, ya estaban el muro, la calle, el jardín. Y a la extrañeza sucede la añoranza. Nos parece recordar y quisiéramos volver allá, a ese lugar en donde las cosas son siempre así, bañadas por una luz antiquísima y, al mismo tiempo, acabada de nacer. Nosotros también somos de allá. Un soplo nos golpea la frente. Estamos encantados, suspensos en medio de la tarde inmóvil. Adivinamos que somos de otro mundo. Es la "vida anterior", que regresa. ${ }^{4}$

\footnotetext{
1 Simposio Repensando o sagrado. Rubem Alves e a teologia da libertação, Mesa redonda: Religión y arte, Universidad Federal de Juiz de Fora, Brasil, 28 de agosto, 2019.

2 Profesor, Facultad Latinoamericana de Teología Reformada, Comunidad Teológica de México. Correo electronico: Icervortiz@yahoo.com.mx.

3 R. Alves, "Poesía", en Cuarto de cachivaches. Trad. de L. Cervantes-O. México, Ediciones Dabar, 2009, p. 89.

4 O. Paz, "La revelación poética”, en El arco y la lira. México, Fondo de Cultura Económica, 1972, p. 133.
} 
La última sección de su tesis doctoral, Towards a theology of liberation (junio de 1968), en la que, sirviéndose de un par de conceptos complementarios (mesianismo humanista y humanismo mesiánico), además de un sólido arsenal tomado de las ciencias sociales, contribuyó a articular el discurso de la naciente teología de la liberación latinoamericana (él es su verdadero padre e iniciador, por si queda alguna duda), se asoman varias líneas de pensamiento y acción cultural subversiva. La propuesta de un "nuevo lenguaje" para la teología la la que redefiniría desde las entrañas en "Del paraíso al desierto") y para las comunidades de fe fue un auténtico primórdio, una semilla pequeñísima, microscópica, que habría de germinar de manera casi inmediata en su segundo libro. La imaginación, junto con la esperanza, estaba llamada a transformar la historia, siempre y cuando la imaginación permaneciese fiel "a las condiciones objetivas y subjetivas del presente histórico", 5 como lo expresaban las ideas de entonces. Se abría así la posibilidad para que la teología, transfigurada en "lenguaje de la imaginación", asimilase todas aquellas expresiones de lo humano que nombran lo ausente: la poesía, la fantasía, el arte, la música, justamente las manifestaciones estéticas, tan ausentes de la mayor parte del quehacer teológico. “¿Qué sería de nosotros sin el auxilio de las cosas que no existen?” (Paul Valéry) fue el mantra repetido por Rubem una y otra vez...

Todo un manifiesto lúdico de fe, un programa de ética libertaria, un testamento anticipado para las nuevas generaciones de creyentes y pensadores que pusieron asomarse, desde el título mismo, a las ventanas Ilenas de aire fresco que comenzaban a henchir los pulmones de Rubem: Tomorrow's Child: Imagination, creativity and Rebirth of Culture (1972). Ese título lo dice casi todo, pues la primera palabra del subtítulo es ya la afirmación de lo que se había instalado en la mente de Alves para dominarla totalmente: el reinado de la imaginación, la libertina habitante de los sueños y de la existencia de todos aquellos, hombres y mujeres, que se niegan a aceptar la realidad tal como es (la lucha contra el realismo como ideología dominante en ese libro fue verdaderamente quijotesca, además de que escribió otros textos importantes al respecto: "Christian realism: ideology of the establishment" en Christianity and Crisis, 17 de septiembre de 1973, es digno de ser recuperado en estos tiempos invisibilizadores de los sueños vigentes). Así, Rubem quedó del lado de los niños, de los locos, de los magos, de los hechiceros, de los bufones, de los utopistas, de quienes juegan el juego más serio sin dejar de sonreír nunca.

El homo ludens que no había sido Alves nació en esos años para invadir su propia vida, la de su familia y la de todos sus allegados (quien habla llegó a serlo después de disfrutar algunos de sus textos con absoluta delectación...) con la felicidad que le otorgaba el trato con las palabras y la forma en que empezó a jugar, a brincar, con ellas (con el significado portugués y castellano de este verbo). La traducción española de ese libro (Hijos del mañana. Imaginación, creatividad y renacimiento cultural. Salamanca, Ediciones Sígueme, 1976) fue un botín tan deseado, tan añorado, que, al leerlo y releerlo por fin completo al menos un par de veces, el perfil del nuevo Alves se iba delineando con características que muchos no pudieron comprender en su momento. Definitivamente, era un libro de la teología de liberación más atípica que alguien pudiera imaginar; otras puertas se cerraron para él, pero no le importó. Su supuesta "traición a la causa" ideológica lo centraría cada vez más en la praxis teopoética (cuando aún no existía ese concepto o corriente) 6 que le permitió, incluso, reencontrarse con viejos compañeros de lucha,

${ }^{5}$ R. A. Alves, Cristianismo: ¿opio o liberación? Salamanca, Ediciones Sígueme, 1973 (Verdad e imagen, 33), p. 232.

${ }^{6}$ Cf. Luana Martins Golin, "A teopoética em Rubem Alves”, en Estudos de Religião, Universidad Metodista de São Paulo, vol. 31, núm. 2, mayo-agosto de 2017, pp. 239-259, https://dialnet.unirioja.es/servlet/articulo?codigo=6342662. Arts, Religion and Culture (https://artsreligionculture.org/) es una comunidad de investigadores presidida por Callid Keefe-Perry que promueve esta corriente teológica mediante conferencias, una revista (Theopoetics, https://artsreligionculture.org/about-the-journal) y otras actividades, entre ellas, el Premio Anual Rubem Alves (https://artsreligionculture.org/the-rubem-alves-award) que se ha otorgado desde 2017. 
como sucedió felizmente con Hugo Assmann (ese otro enamorado de la educación para la libertad que fue uno de sus más duros críticos en su momento).7

Ya desde entonces, el profesor invitado de ética al Seminario Union de Nueva York, donde pocos años atrás había defendido una tesis de maestría sobre el proceso revolucionario brasileño (1964, y que gracias a los desvelos de Antonio Vidal Nunes ha podido por fin leerse a placer, aun contra las salvedades de su autor por la posibilidad de conocer los inicios, muy militantes, de su reflexión teológica), puso en marcha los dispositivos más audaces para jugar con sus cuentas de vidrio poéticas y teológicas y así armar nuevos collares que, al salir de su mano (como aprendió a hacerlo gracias a Hermann Hesse en El juego de los abalorios) ofrecerían grandes momentos de placer a adultos y después a niños/as de todas las edades. Sería, desde entonces, el magister ludi por antonomasia del pensamiento religioso latinoamericano y el primer forjador de artefactos verbales exclusivamente dedicados a producir felicidad. Al valorar años después lo escrito en Hijos del mañana (aparecido en portugués hasta con el título A gestação do futuro), sus palabras sonaron francas y diáfanas:

\begin{abstract}
Yo sólo quería seducir: invitar al lector a ver el mundo a través de mis ojos. Y a que amen este mundo. En todo lo que se escribe siempre hay un deseo de conseguir con/spiradores: unos pocos que respiren el mismo aire. Por eso el texto ha de tener sabor, para que el cuerpo quede hechizado. Pero yo tenía poco respeto por esas cosas. Tanto, que, si pudiese reescribir el libro, incluiría un capítulo sobre "La función política de la belleza", porque creo que las personas luchan mejor cuando están poseídas por visiones de cosas bellas. De ahí que no pueda imaginar una teología de la liberación que no se presente como algo estético, como obra de arte, fragmento de paraíso, sacramento sabroso. Quiero una teología que esté más cerca de la belleza que de la verdad, porque de la visión de la belleza surgen los amantes, pero sobre la visión de la verdad se construyeron las inquisiciones. ${ }^{8}$
\end{abstract}

La sucesión de textos y libros se vino en cascada, ya con ese enfoque lúdico-poético que aún se resistía, pero que se vio antecedido por aportaciones atípicas también, a la teología de la liberación. Así podrían clasificarse y $O$ enigma da religião (1975), Protestantismo e repressāo (1979) por ejemplo, y hasta O que é religião (1981) y O suspiro dos oprimidos (1984). Así despegó Rubem Alves en un viaje sin retorno que lo llevó a viajar por los senderos inesperados e inexplicables de la imaginación desatada, incontenible, que lo sorprendía todo el tiempo con nuevos giros y variaciones. Fue precisamente esta palabra la que presidió, dominó y organizó su pensamiento en Variações sobre a vida e a norte, donde su centro, como ya se anunció desde Hijos del mañana también, sería el cuerpo humano, espacio de gracia y de maldad, de bendición y de muerte institucional, de felicidad y maldición, muchas de las veces al mismo tiempo; asimismo el deseo, el erotismo y la belleza permean esas realidades en momentos hasta incompatibles. "Los jugadores/ teólogos tuvieron la inexplicable idea de que el destino del cuerpo dependía de su capacidad para decir la verdad y no de la gracia de Dios, la cuenta encantada de donde el cuerpo recibe sus sonrisas y sus esperanzas". 9 La conjunción de todos estos elementos modificaron para siempre su mirada, lanzada ahora sobre horizontes distintos, inimaginables con anterioridad, a una enorme distancia de la solemnidad de la religión institucional enajenante:

Llegamos a la conclusión de que quien, de alguna manera fue arañado por el gran misterio, como Jacob, conoce el terror y la fascinación de lo sagrado, y descubre

\footnotetext{
${ }^{7}$ Cf. José Mario Méndez, "El placer de aprender. Aportes para una pedagogía erótica", en Pasos, Departamento Ecuménico de Investigaciones, núm. 154, enero-marzo de 2012, pp. 51-71, http://deicr.org/IMG/pdf/pasos_no._154.web.pdf.

${ }^{8}$ R. Alves, "Memórias", en O quarto do mistério. $2^{\text {a }}$ ed. Campinas, Papirus-Speculum, 1995, p. 198. Este texto es el prólogo de $A$ gestação do futuro. Campinas, Papirus, 1987. Énfasis agregado.

9 La teología como juego. Buenos Aires, La Aurora, 1981, p. 78.
} 
que todo lo demás no es sagrado sino juego, hacer como si..., sacramento, aperitivo, ni divino ni demoniaco, cosas del cuerpo —esta burbuja de jabón tan frágil pero que amamos de todo corazón y por cuya eternidad continuamos orando. "Creo en la resurrección del cuerpo". Un cuerpo que juega merece vivir eternamente. $Y$ descubrimos algo curioso: que el lenguaje teológico, lenguaje del cuerpo sobre sí mismo, se ríe de los bretes académicos en que los teólogos serios lo colocaron, voltea cercos y va cantando por el mundo afuera, en los poemas de los poetas, en las canciones de los cantores, en las confidencias de los amantes, en los cuentos de los literatos, en los chistes de los humoristas y payasos, jugando siempre y diciendo que a causa del Gran Misterio es posible reír y amar.10

Poesia, profecia, magia concentró los primeros hallazgos que su búsqueda aleatoria le permitió alcanzar. La sucesión de encuentros poéticos sería casi infinita, pues al estilo acumulativo que ese volumen forjó, la estructura tripartita de ese libro muestra la forma en que Alves se fue auto-descubriendo como un autor literario que había colocado a la teología en una especie de "suspensión operativa" para volver a ella de manera casi inmediata y reincorporarla progresivamente en una suerte de reencuentro de naturaleza dialéctica, ya libre de las amarras institucionales. Quien escribe estas líneas reconoce que no tuvo a su alcance esta producción literario-religiosa en las fechas de la redacción de su tesis de maestría (como tampoco tuvo acceso a As contas de vidro e o fio de nylon, 1997; allí se cometió el error de afirmar que 0 poeta, o guerreiro, o profeta [1990] es una versión ampliada de Poesia, profecia, magia, cuando en realidad representa una etapa muy avanzada de lo que Alves llegó a hacer como prosista consumado, prosista de intensidades, desde la sugerente propuesta del escritor mexicano Alberto Ruy Sánchez"11), por lo que, de manera intuitiva, y sondeando entre los demás libros a su alcance, especialmente $O$ que é religião (1981), se trazó una línea escritural que desembocaría en otras producciones tales como Creio na resurreicão do corpo (1982) y Pai Nosso (1983), que manifiestan, en conjunto, una suerte de delirio para el nuevo escritor que estaba surgiendo dentro del propio Alves, algo así como le sucedió a Fernando Pessoa, quien sintió a su propio maestro nacer dentro de sí. En este caso, bien podría decirse que acaso la lectura profunda de Guimarães Rosa contribuyó de manera sólida para el alumbramiento del Alves escritor-apartadode-cualquier-forma-de-ortodoxia. Con esto queremos decir que en esos años nació el Rubem Alves inesperado, que muy poca gente (incluyéndolo a él mismo) imaginó que despegaría como escritor notable.

Esos años coinciden, como se ha dicho ya, con su colaboración en Tempo e Presença, en donde la presencia de su amigo Jether Pereira Ramalho fue fundamental. En el núm. 183, de junio de 1983, publicó un texto (en un formato literario que después denominaría crónica) acerca de la forma en que es posible aproximarse a la poesía. La valoración de la poesía como forma de conocimiento y apropiamiento del mundo, así como su cambio de lenguaje, hacen de este texto, desde su título ("Magia"), un auténtico manifiesto estético personal. Con todo, el sabor y el saber teológicos aparecen una y otra vez en esta nueva forma de expresión que dejó una profunda huella en su país, adonde también desplegó un esfuerzo educativo de enormes proporciones. Esta traducción va acompañada de algunas acotaciones que permiten situar lo dicho por Alves en el contexto de su vida y obra:

Vamos a jugar a "la escuelita". Es una clase de portugués y la profesora, más moderna, quiere hacer pensar a los niños. Trajo un poema. Quiere hacer pensar a esas cabecitas. Es necesario que las ideas sean claras y distintas. [La fórmula que

\footnotetext{
10 Ibid., p. 143.

" Cf. Mario Gingras, La prosa de intensidades en la narrativa de Alberto Ruy Sánchez: un habitar poético del mundo. Tesis de Maestría en Estudios Hispánicos, Universidad de Montréal, noviembre de 2006, https://papyrus.bib.umontreal.ca/xm/ui/bitstream/handle/1866/18151/Gingras_Mario_2006_memoire.pdf?se quence=18Tis Allowed $=y$.
} 
Alves utilizó insistentemente para referirse al lenguaje formal de la ciencia.] Que se sepa bien lo que se ha leído. Concientización. [Sin referirse explícitamente a Paulo Freire, Alves esboza una crítica sutil a la corriente pedagógica de este gran autor.] Y dice: "Mucha atención. Voy a comenzar la lectura". Y habla, con voz firme, con las sibilancias y las erres arrastradas. Para que los sonidos no engañen a los oídos, que éstos no engañen a la razón, y ésta no engañe al cuerpo.12

El poema de Carlos Drummond de Andrade que glosa a continuación y que es leído por esta maestra hipotética empeñada en interpretar, queda muy lejos, lamentablemente, de las cabezas infantiles que lo ven alejarse para siempre debido al empeño de penetrar en su argumentación, en vez de profundizar en lo poético propiamente dicho. La crítica alvesiana no es solamente pedagógica, es de naturaleza estética, pues el alumbramiento de un niño como lector y experimentador de la poesía, definitivamente debía ir por otros canales epistemológicos y educativos:

Interpretar. ¡Ah! Si ella hubiera dicho "el gis es blanco" no sería necesaria ninguna interpretación. La interpretación es algo que se dice después de oír una cosa confusa. Luz que se enciende en la oscuridad. Este hilo aceitoso que escurre por la barbilla del niño, y escurre por la calle, y escurre por la ciudad, por supuesto que necesita ser interpretado. En caso contrario, un alma desinformada llamaría a los bomberos para limpiar y los choferes comenzarían a derrapar en el aceite que se untó en el asfalto. Es preciso decir que eso es una figura del lenguaje. Una cosa dicha de forma nebulosa, porque el escritor, pobre hombre, no se acordó de las palabras claras y distintas. Si hubiera leído sobre Descartes, seguramente no se habría dedicado a la poesía. Preferiría el habla científica, los análisis de los dolores, cada cosa en su lugar, los aceites en los recipientes y en los estómagos, y en la calle los paquetes enmarañados de cigarros, las Ilantas, las tarjetas de visita. El remedio aceitoso no vive allí. Pobre poeta. Confuso. Vamos en su auxilio, interpretaciones a la orden. Para espantar las brumas y poner luz en la sombra. ${ }^{13}$

En pocas palabras, la interpretación mata las posibilidades de que el lector imberbe, primerizo, que se acerca por primera vez a la poesía, se deje tocar por ésta, y su cuerpo completo experimente lo que ella puede hacer con lo humano, con su sensibilidad llena de enorme potencial artístico, estético. Se instalaba así, en el ambiente, la creencia negativa absoluta en la inutilidad del arte que, como el juego, no producen cosas igualitarias sino únicamente placer para el cuerpo, para la mente, para la totalidad de la persona. La conclusión de Alves es radical: ese momento sublime en el que palpitó de manera real la posibilidad de que el poema hiciera volar el alma del pequeño lector encima de las realidades fácticas y "productivas" se perdió irremediablemente por causa de la ansiedad pedagógica por desmenuzar el acto poético como si se tratase de una disección quirúrgica:

¡Ah! Como son mejores las palabras claras y distintas. Dicen las cosas tal como son realmente, sin deseo y sin emoción. Antes, al leer el poeta, la viscosidad del remedio lamía las manos de la gente, y el quejido débil del niño retorcía nuestros nervios. Pero ahora, desapareció la confusión. Todo mundo sabe que el texto con palabras claras y distintas debe ser mejor que el texto confuso. Por lo tanto, podemos dejar definitivamente el poema en la papelera y quedarnos con la interpretación....14

Lo contrario de todo esto es practicado en Poesia, profecia, magia. La primera sección explora y lleva de la mano al lector por los senderos de sus descubrimientos poéticos dominados

\footnotetext{
12 R. Alves, "Magia”, en Tempo e Presença, junio de 1983, p. 7.

13 Ídem.

14 Ídem.
} 
por la figura tutelar de T.S. Eliot y la mirada submarina que se acerca a la luz fracturada y al Coro de "La Roca" que se conduele de la infamia con que es tratada la Palabra, y la divina en particular, en este mundo grotesco y caótico. También se practica una relectura del acto de comer las palabras, de dejarse alimentar por las palabras que fabrican mundos nuevos, dentro y fuera de las personas. El poeta estadunidense Robert Frost (1874-1963) fue su tutor en esta travesía existencial adonde la "nostalgia indefinible" es quizá la realidad más dominante que él comparte con sus nuevos lectores. Las frases cortas, directas, muestran cómo este autor fue aprovechando y comprendiendo las pausas del lenguaje para deslizar su pensamiento reptante. Estamos en el laboratorio de gestación del escritor-poeta, del escritor-demiurgo que ha descubierto para sí mismo el grandioso poder sacramental, hechizante, de las palabras:

Magia. Poesía. En el fondo, la misma cosa. Palabras que hacen cosas [los "actos de habla" de la lingüística formal]. Palabras que son cosas. El mundo se hace diferente. $Y$ los escenarios mudos se convierten en sacramentos, extensiones del cuerpo, carne de mi carne, habitaciones de sonrisas. Por un corto momento desaparece el tiempo y la distancia. Estamos allá, a la vera de los bosques bellos, sombríos, hondos, por el hechizo de las palabras. Se acaba el encanto, como la neblina que se va. Pero queda el deseo, en el inmenso vacío que se abre...

la nostalgia de cada hoja,

cada tronco de un árbol... [...]

Cada vez que las mismas palabras se repiten, renacen las sonrisas, las lágrimas, la fascinación, el temblor del cuerpo.15

El conjuro del lenguaje cumple su función reencantadora del mundo (¿Alves vs. Weber?), yendo y viniendo del misterio de las cosas hacia la realidad que lo esconde. Husmear de esta manera en las asociaciones íntimas de las cosas contribuye a desvelar lo que toda realidad encierra, pero que hay que atrapar de manera libre para ser poseídos. La segunda parte del libro indaga en la profecía, en los resquicios religioso-poéticos que no ahogan el pensamiento sino que lo afinan, que lo hacen capaz de ser portador, también, del misterio irreductible, indomable, que se esconde y se resiste a ser utilizado en el mundo de las formas insensibles. Porque en todas partes acecha la belleza y es preciso someterse a ella.

La belleza es infinita;

ella nunca se satisface con su forma final.

Cada experiencia de belleza es el inicio de un universo.

El mismo tema debe repetirse,

cada vez de una forma diferente.

Cada repetición es una resurrección,

un eterno retorno de una experiencia pasada

que debe permanecer viva.

El mismo poema, la misma música, la misma historia...

Y, mientras tanto, nunca es la misma cosa.

Pues, en cada repetición, la belleza renace nueva y fresca

como el agua que brota en la mina. ${ }^{16}$

15 R. Alves, Poesia, profecia, magia. Meditações. Río de Janeiro, Centro Ecumênico de Documentação e Informação, 1983, pp. 9, 15.

16 R. Alves, Lições de feitiçaria. Meditações sobre a poesía. São Paulo, Edições Loyola, 2003, p. 197. 